\title{
Synthesis and cytotoxic activity of novel chromenes
}

\author{
Babak Heidary Alizadeh, ${ }^{a}$ Seyed Nasser Ostad, ${ }^{b}$ Alireza Foroumadi, ${ }^{c}$ Mohsen Amini, ${ }^{c}$ Reza \\ Dowlatabadi, ${ }^{c}$ Latifeh Navidpour, ${ }^{c}$ and Abbas Shafiee ${ }^{c} *$
}
${ }^{a}$ Iranian Research Institute of Plant Protection (IRIPP), Shahid Chamran Express Way, Yaman St., No 1, P. O. Box: 1454, Tehran, Iran
${ }^{b}$ Department of Pharmacology and Toxicology, Faculty of Pharmacy, Tehran University of Medical Sciences, Tehran 14174, Iran
${ }^{c}$ Department of Medicinal Chemistry, Faculty of Pharmacy and Pharmaceutical Sciences
Research Center, Tehran University of Medical Sciences, Tehran 14174, Iran

E-mail: ashafiee@ams.ac.ir

\begin{abstract}
With the aim of discovering potential cytotoxic agents, a new series of substituted 4-chromenes were synthesized in three steps starting from the readily available 4-chromanone 3 . Alkylation of compound 3 afforded alkyne 4-chromanone 5, which on subsequent cyclization provided pyranochromene 10. Reaction of compounds 5 and $\mathbf{1 0}$ with Grignard reagents yielded the desired compounds 7, 8a-d/9a-9d, 12a-b and 14a-c/15a-c. The synthesized compounds were evaluated for their cytotoxic activity on three different cell lines, namely HT29, T47D and L929 and most of them were shown to be relatively good with $\mathrm{IC}_{50}=100-130 \mu \mathrm{M}$. Among them, 14b/15b and 8c/9c were the most potent ones with the $\mathrm{IC}_{50}=92.28 \pm 16.84$ (on HT29) and $94.48 \pm 15.37 \mu \mathrm{M}$ (on T47D), respectively.
\end{abstract}

Keywords: Synthesis, chromene, cytotoxic activity 


\section{Introduction}

Chromenes are structurally simple compounds belonging to a large class of molecules known as benzopyranes and chroman-4-one moiety is an integral part of many natural products. These compounds and related derivatives have diverse biological activities, including antitumor, leishmanicidal, bacteriostatic that makes these compounds attractive for further backbone derivatisation and screening as a novel therapeutic agent. ${ }^{1-3}$ Chroman-4-one derivatives have also drawn much attention due to their anti-human-immunodeficiency-virus (HIV-1) activity. ${ }^{4}$ Recently, several new naturally occurring chromenes, including Licuformodiol A, B have been isolated from the cytotoxic chloroform-soluble fraction of Ficus formosana and carpachromene exhibited significant cytotoxicity against $\mathrm{HepG} 2, \mathrm{PLC} / \mathrm{RRF} / 5$ and Raji cell lines in vitro. ${ }^{5}$ Furthermore, considerable interest has recently been shown toward pharmacological activity exhibited by naphtopyrane derivatives which have been isolated from liches plant. ${ }^{6}$ Lichen $4 \mathrm{H}$ 4-Chromenone derivatives have also shown to be inhibitors of protein kinases. ${ }^{7} 4 \mathrm{H}$-Chromene3-carboxylate was found to induce Cytochrome c release from the mitochondria of intact cells, which Cytochrome c release is a central step in the apoptosis induced by many death stimulations. ${ }^{8}$ More recently, some amino $4 H$-chromenes were found to induce nuclear fragmentation and PARP cleavage as well as to arrest cells at the G(2)M stage and to induce apoptosis. $^{9}$<smiles>COc1ccc(C2COc3ccc4c(c3C2)OC(C)(C)C=C4)c(OC)c1O</smiles><smiles>CC1(C)C=Cc2ccc3oc(=O)ccc3c2O1</smiles>

Seselin<smiles>COC1=CC2OC(C)(C)C=CC2c2c1c(=O)c1ccccc1n2C</smiles>

Acronycine

Figure 1. Chemical Structure of Chromene analogues

In a search to find new cytotoxic agents structurally related to 2,2-dimethyl- $2 H$-chromenes (Glyasperin, Seselin, Acromycine, Fig.1), herein we report the synthesis and cytotoxic activity of new chromene derivatives as potential anticancer agents. 


\section{Results and Discussion}

\section{Chemistry}

Chromenes are generally synthesized by condensation reaction of hydroxyphenol and dimethylacrylic acid in the presence of a Lewis acid. ${ }^{10}$ Thus the key intermediate $\mathbf{3}$ was synthesized through the reaction of resorcinol (1) with equimolar amount of 3,3-dimethylacrylic acid (2) in the presence of three equivalent of trifluoromethanesulfonic acid. ${ }^{11}$ Treatment of compound 3 with 2-methyl-3-butyn-2-ol (4) and trifluoroacetic anhydride in the presence of DBU and $\mathrm{CuCl}_{2} \cdot \mathrm{H}_{2} \mathrm{O}$ gave 5 through the triflate intermediate. ${ }^{12}$ Reaction of compound 5 with $p$ chloropheylmagnesim bromide ${ }^{13}$ in refluxing ether gave the corresponding alcohol $\mathbf{6}$. Conversion of the alcohol 6 to the corresponding olefin 7 was accomplished by acidic dehydration in refluxing $1 \mathrm{~N} \mathrm{HCl}$. Similarly reaction of substituted benzylmagnesium chloride with compound $\mathbf{5}$ followed by dehydration gave a mixture of exo $(\mathbf{8 a}-\mathbf{d})$ and endo $(\mathbf{9 a}-\mathbf{d})$ isomers (Scheme 1).
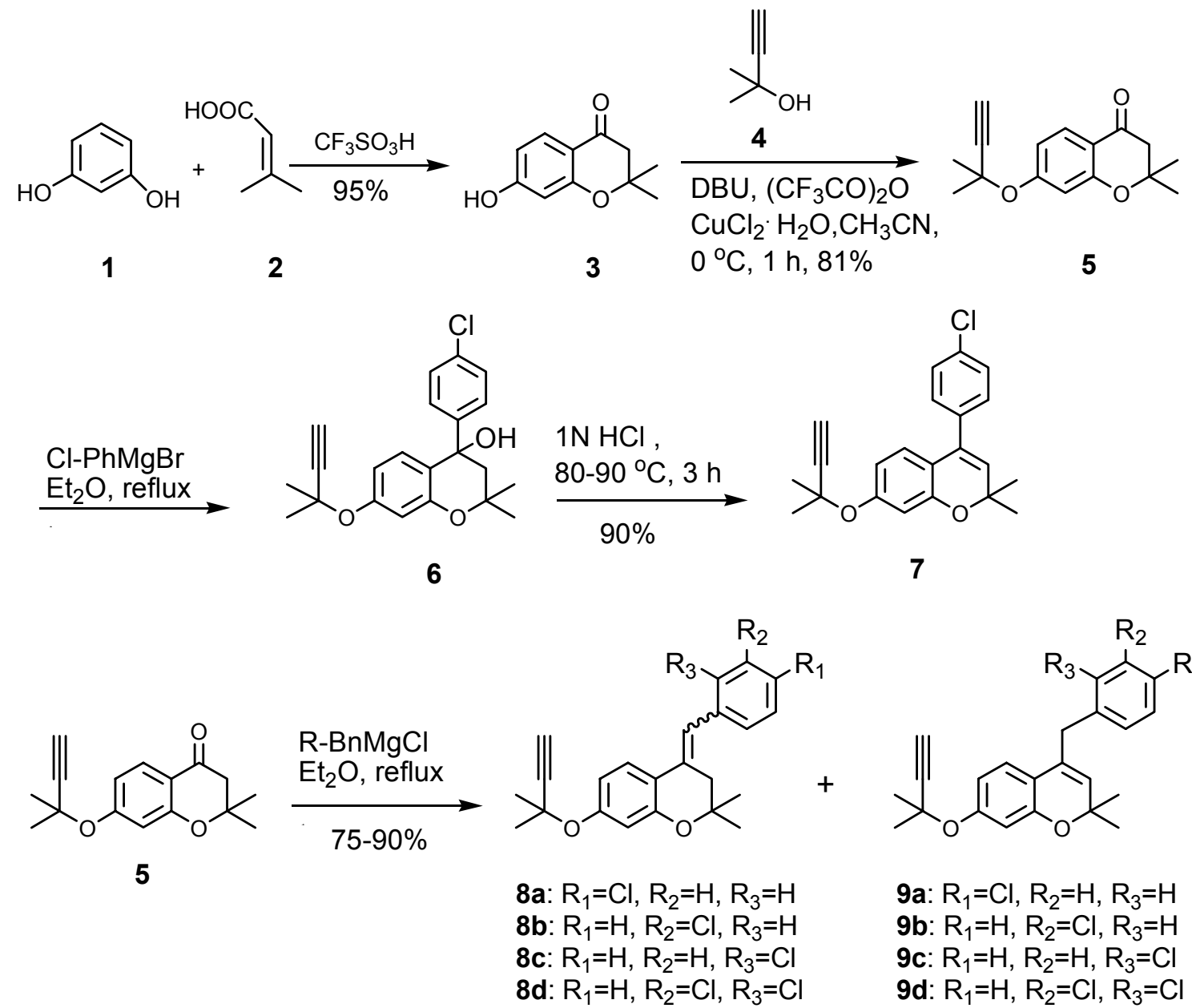

Scheme 1. The synthesis of compounds 7 and 8a-d, 9a-d 
In addition, exo isomers (8a-d) were a mixture of $E$ and $Z$ isomers. It should be noted that none of these isomers could be separated by conventional methods. ${ }^{14}$ Differentiation between exo and endo isomers as well as $E$ and $Z$ of exo isomers were based on the ${ }^{1} \mathrm{H}-\mathrm{NMR},{ }^{13} \mathrm{C}-\mathrm{NMR}$ and NOESY experiments. In ${ }^{1} \mathrm{H}-\mathrm{NMR}$, observation of a doublet at 2.50 to $2.65 \mathrm{ppm}\left(3-\mathrm{CH}_{2}\right.$ of compound 8) and a singlet at 3.65 to $3.80 \mathrm{ppm}$ (benzylic $\mathrm{CH}_{2}$ of compound 9) showed the existence of both endo and exo isomers respectively, in the ratio of the 56:44 to 60:40. Moreover, the exo product appeared to be a mixture of $E$ and $Z$ steroisomers which were assigned based on the anisotropic effect of substituted phenyl ring on $\mathrm{H}_{5}$ of the $Z$ isomer. In the $E$ isomer $\mathrm{H}_{5}$ of compound 8 appeared as a doublet at 7.50 to $7.55(J=8.5 \mathrm{~Hz})$. However in $Z$ isomer, it appeared at 7.47 to $7.53 \mathrm{ppm}(J=8.5 \mathrm{~Hz})$. The ratio of $E$ to $Z$ sterioisomers of compounds 8a-d were measured to be $95: 5$ to $65: 35$. The configuration of the $E$ isomer as a major product was confirmed through 2D NOESY NMR spectroscopy and the assignment of stereochemistry of compound $\mathbf{8 a}$ is consisted with the observed strong cross peak between $\mathrm{H}_{5}$ and vinylic- $\mathrm{H}(\mathrm{Ar}-\mathrm{CH}=\mathrm{C})$ and relatively weak cross peak between $\mathrm{H}_{3}$ and ortho- $\mathrm{H}$ phenyl ring. In addition, in ${ }^{13} \mathrm{C}-\mathrm{NMR}$ the $3-\mathrm{CH}_{2}$ of exo and benzylic $\mathrm{CH}_{2}$ of endo isomers appeared as two separate signals at 37.2-37.5 and 34.9-37.2. The benzylic $\mathrm{CH}$ (exo isomer) and olefinic $\mathrm{CH}$ (endo 3-CH) appeared as two separate singlets at 118.9-120.7 and 123.3-123.6 respectively. The Dept-135 and Dept-90 experiments confirmed the mentioned $\mathrm{CH}_{2}$ and $\mathrm{CH}$ groups.

Heating of the compound 5 in $N, N$-dimethylaniline at $180{ }^{\circ} \mathrm{C}$ for 3 hours afforded the cyclized compound 10. ${ }^{9,15}$ Reaction of substituted phenylmagnesium bromide with compound 10 and subsequent dehydration of the intermediate $\mathbf{1 1}$ with $1 \mathrm{~N} \mathrm{HCl}$ gave the chromene $\mathbf{1 2}$ (a-b). Compounds 14a-c/15a-c were synthesized by the reaction of compound 10 with appropriate substituted benzylmagnesium chloride and subsequent dehydration. Compounds 14a-c (exo, $E$ and $Z$ mixture)/15a-c (endo) could not be separated by conventional methods. The structure of compounds 14 and 15 were established (Scheme 2) by ${ }^{1} \mathrm{H}-\mathrm{NMR},{ }^{13} \mathrm{C}-\mathrm{NMR}$ and NOESY experiments similar to 8 and 9. 


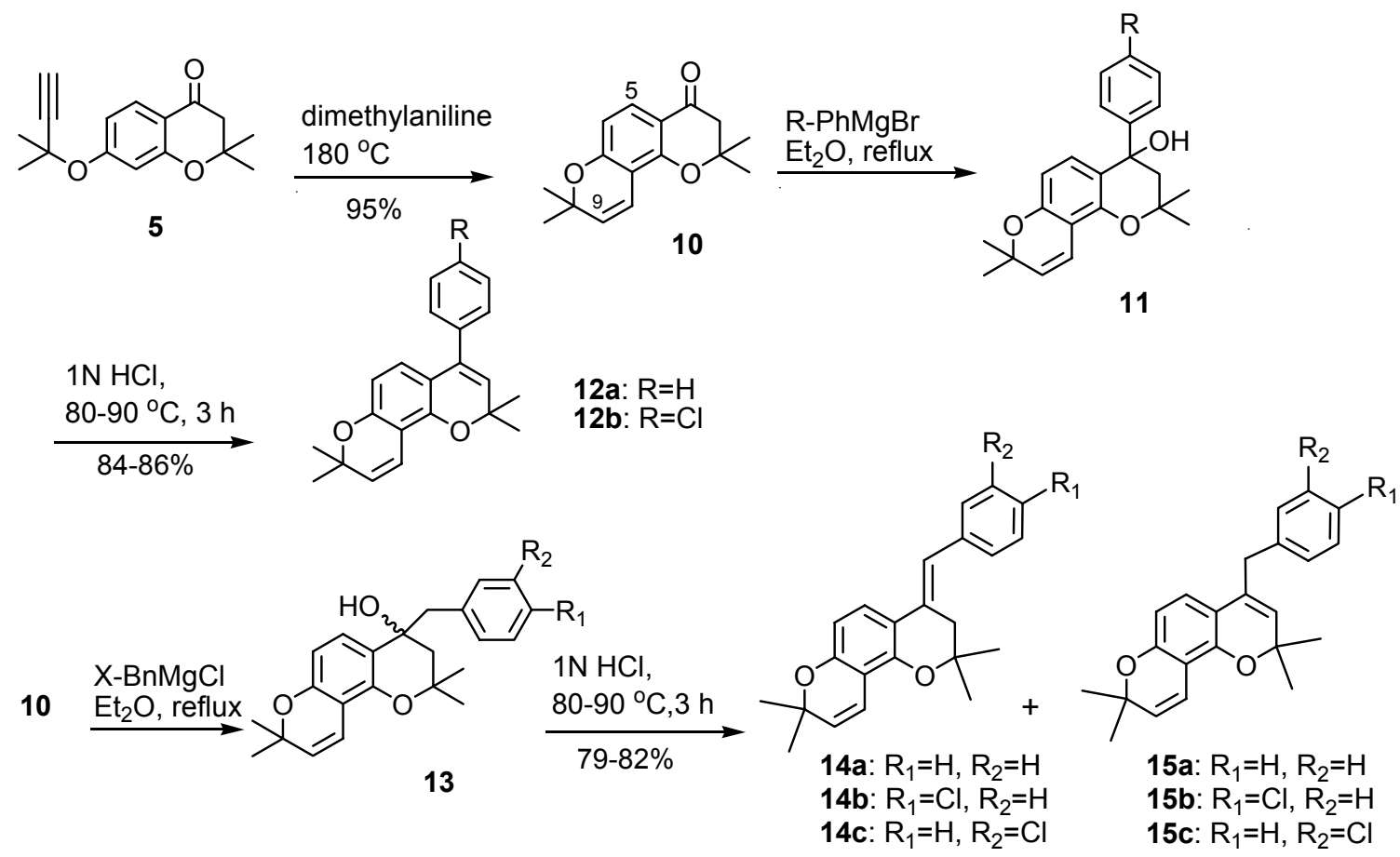

Scheme 2. The Synthesis of compounds 12a-b and 14a-c, 15a-b

\section{Cytotoxicity}

The experiments for determination of cytotoxicity of the chromene derivatives 7 , mixture of 8a-d/9a-d, 12a-b and 14a-c/15a-c were performed on the three cell lines namely HT29 (colon carcinoma cells), T47D (breast carcinoma cells) and L929 (mouse fibroblast) obtained from Pasteur Institute (Tehran). The experiment was carried out in 96-well culture dishes and cells were seeded at the density of $6 \times 104$ cells/well. The stock solutions of chromene derivatives in DMSO were diluted with media and added into each well of dish at final concentrations of 5, 25, $75,125,250 \mu \mathrm{M}$. Culture mediums containing DMSO in concentration equal to those incubations treated with the tested compound served as control. Cell incubation was then kept at $37^{\circ} \mathrm{C}$ under an atmosphere of $95 \%$ air: $5 \% \mathrm{CO}_{2}$. The response of cells to chromene derivatives was evaluated by determining the cell survival using MTT assay after $24 \mathrm{~h}^{16}$ Survival was scored by comparing treated cells with the tested compounds to untreated cells (control) and is expressed as percentage of cell survival. $\mathrm{IC}_{50}$ of these compounds in three cancer cell lines in comparison to methotreaxate as a reference drug is summarized in Table 1. 
Table 1. $\mathrm{IC}_{50}(\mu \mathrm{M} \pm$ S.D. $)$ of the synthesized compounds against different cell lines.<smiles>C#CC(C)(C)Oc1ccc2c(c1)OC(C)(C)C=C2c1ccc(Cl)cc1</smiles>

7

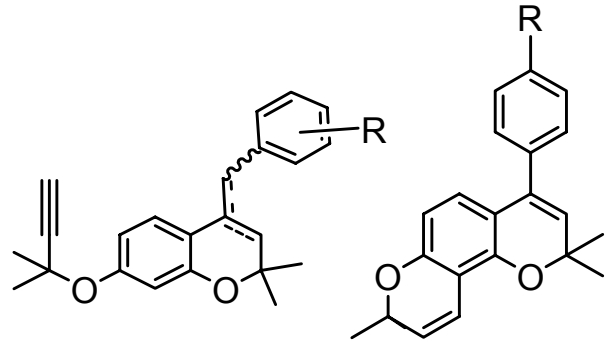

$8 \mathbf{a}-\mathbf{d} / 9 \mathbf{a}-\mathbf{d}$

12a-b

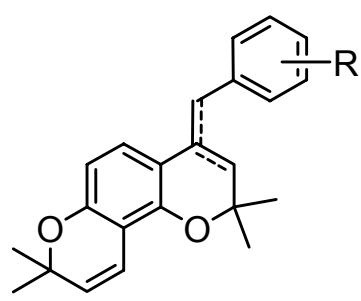

$14 a-c / 15 a-c$

\begin{tabular}{ccccc}
\hline Compound No. & R & HT29 & T47D & L929 \\
\hline $\mathbf{7}$ & - & $161.52 \pm 38.89$ & $173.87 \pm 10.27$ & $166.64 \pm 54.2$ \\
$\mathbf{1 2 a}$ & $\mathrm{H}$ & $104.81 \pm 6.61$ & $128.15 \pm 1.75$ & $109.43 \pm 4.35$ \\
$\mathbf{1 2 b}$ & $4-\mathrm{Cl}$ & $105.16 \pm 14.58$ & $124.33 \pm 15.98$ & $108.58 \pm 6.09$ \\
$\mathbf{8 a} / \mathbf{9 a}$ & $4-\mathrm{Cl}$ & $104.4 \pm 48.18$ & $113.00 \pm 8.57$ & $103.50 \pm 6.16$ \\
$\mathbf{8 b} / \mathbf{9 b}$ & $3-\mathrm{Cl}$ & $127.44 \pm 13.69$ & $182.43 \pm 33.21$ & $130.03 \pm 30.37$ \\
$\mathbf{8 c} / \mathbf{9 c}$ & $2-\mathrm{Cl}$ & $104.58 \pm 9.11$ & $94.48 \pm 15.37$ & $105.47 \pm 8.15$ \\
$\mathbf{8 d} / \mathbf{9 d}$ & $2,3-\mathrm{Cl}_{2}$ & $115.05 \pm 11.98$ & $114.9 \pm 17.17$ & $107.14 \pm 7.96$ \\
$\mathbf{1 4 a} / \mathbf{1 5 a}$ & $\mathrm{H}$ & $133.81 \pm 13.97$ & $140.05 \pm 13.89$ & $247.32 \pm 29.69$ \\
$\mathbf{1 4 b} / \mathbf{1 5 b}$ & $4-\mathrm{Cl}$ & $92.28 \pm 16.84$ & $102.17 \pm 9.01$ & $103.56 \pm 18.2$ \\
$\mathbf{1 4 c} / \mathbf{1 5 c}$ & $3-\mathrm{Cl}$ & $115.8 \pm 23.29$ & $119.04 \pm 8.71$ & $112.03 \pm 15.26$ \\
Methotrexate & - & $0.23 \pm 0.02$ & $0.16 \pm 0.09$ & $0.46 \pm 0.03$ \\
\hline
\end{tabular}

As shown in Table 1, for HT29 the most active compound was $\mathbf{1 4 b} / \mathbf{1 5 b}$ with $\mathrm{IC}_{50}=92.28 \pm 16.84 \mu \mathrm{M}$ and compounds $\mathbf{1 2 a}, \mathbf{1 2 b}, \mathbf{8 a} / \mathbf{9 a}$ and $\mathbf{8 c} / \mathbf{9 c}$ with similar activities were more active than the rest. In T47D the most active compound was $\mathbf{8 c} / \mathbf{9 c}$ with $\mathrm{IC}_{50}=94.48 \pm 15.37$ $\mu \mathrm{M}$ and in L929 several compounds had activities in the range of $103.50 \pm 6.16$ to $109.43 \pm 4.35$. Finally, compounds $\mathbf{8 c / 9 c}$ and $\mathbf{1 4 b} / \mathbf{1 5 b}$ showed relatively good activities in all tested cell lines.

In conclusion, through this study we have synthesized several chromenes $(\mathbf{8 a}-\mathbf{d} / \mathbf{9 a}-\mathbf{d}, \mathbf{1 2} \mathbf{a}-\mathbf{b}$ and $14 \mathbf{a}-\mathbf{c} / 15 \mathbf{a}-\mathbf{c})$ and demonstrated that they are potential anticancer agents.

\section{Experimental Section}

General Procedures. Melting points were determined on a Kofler hot stage apparatus. ${ }^{1} \mathrm{H}-\mathrm{NMR}$ spectra were measured using a Bruker $500 \mathrm{MHz}$ spectrometer and chemical shifts are expressed as $\delta(\mathrm{ppm})$ relative to tetramethylsilane as internal standard. The IR spectra were obtained on a Shimadzu 470 spectrophotometer (potassium bromide disks). All substrates and reagents were 
obtained from Merck and Aldrich Chemical Co. MS spectra were obtained with a Finnigan MAT TSQ-70 spectrometer. Elemental microanalyses were within $\pm 0.4 \%$ of theoretical value for $\mathrm{C}$ and $\mathrm{H}$.

2,2-Dimethyl-7-(2-methylbut-3-yn-2-yloxy)-chroman-4-one (5). To a solution of 2-methyl-3butyn-2-ol $(4,2 \mathrm{~mL}, 20.83 \mathrm{mmol})$ in anhydrous acetonitrile $(10 \mathrm{~mL})$ under argon and cooled in an ice-salt bath at $-5^{\circ} \mathrm{C}$, was added DBU $(4.7 \mathrm{~mL}, 31.25 \mathrm{mmol})$ drop-wise. Trifluoroacetic anhydride $(2.9 \mathrm{~mL}, 20.83 \mathrm{mmol})$ was added over a $30 \mathrm{~min}$ period while keeping the temperature at less than $0^{\circ} \mathrm{C}$. The solution was allowed to stir at $0^{\circ} \mathrm{C}$ for $1 \mathrm{~h}$ before addition of 3 . To a solution of $3(1 \mathrm{~g}, 5.2 \mathrm{mmol})$ in $\mathrm{CH}_{3} \mathrm{CN}(10 \mathrm{~mL})$ under argon and cooled in an ice-salt bath $\left(-5^{\circ} \mathrm{C}\right)$ was added DBU $(1.1 \mathrm{~mL}, 7.8 \mathrm{mmol})$ and $\mathrm{CuCl}_{2} \cdot 2 \mathrm{H}_{2} \mathrm{O}(44 \mathrm{mg}, 0.44 \mathrm{mmol})$ and stirred for $30 \mathrm{~min}$. This solution, maintained at $-5^{\circ} \mathrm{C}$, was added to the 2-methyl-3-butyn-2-triflate solution over a 50 min period while keeping the temperature below $0^{\circ} \mathrm{C}$. After stirring for $30 \mathrm{~min}$ at $0^{\circ} \mathrm{C}$, water was added and the mixture was concentrated at reduced pressure and the residue was extracted with EtOAc $(3 \times 50 \mathrm{~mL})$. The combined organic phase was washed with $1 \mathrm{~N} \mathrm{HCl}$ $(3 \times 50 \mathrm{~mL})$, saturated $\mathrm{NaHCO}_{3}$, and brine. After drying $\left(\mathrm{Na}_{2} \mathrm{SO}_{4}\right)$, the solvent was removed under reduced pressure to give a residue, which was purified by column chromatography (silicagel, $30 \mathrm{~g}$ ) eluted by hexane/ethyl acetate (4:1) to provide the compound 5 (1.09 $\mathrm{g}$, $4.2 \mathrm{mmol}, 81 \%)$ as pale yellow oil as well as starting compound $3(0.1 \mathrm{~g}, 0.5 \mathrm{mmol}, 10 \%)$. ${ }^{1} \mathrm{H}-$ NMR $\left(\mathrm{CDCl}_{3}\right) \delta: 1.43\left(\mathrm{~s}, 3 \mathrm{H}, 2-\mathrm{CH}_{3}\right), 1.44\left(\mathrm{~s}, 3 \mathrm{H}, 2-\mathrm{CH}_{3}\right), 1.68\left(\mathrm{~s}, 3 \mathrm{H}, \mathrm{C} \equiv \mathrm{CCCH}_{3}\right), 1.69$ (s, 3H, $\left.\mathrm{C} \equiv \mathrm{CCCH}_{3}\right), 2.63\left(\mathrm{~s}, 2 \mathrm{H}, 3-\mathrm{CH}_{2}\right), 2.66(\mathrm{~s}, 1 \mathrm{H}, \mathrm{CH} \equiv \mathrm{C}), 6.73\left(\mathrm{~d}, 1 \mathrm{H}, J=2.3 \mathrm{~Hz}, \mathrm{H}_{8}\right), 6.77(\mathrm{dd}, 1 \mathrm{H}$, $\left.J=2.3 \mathrm{~Hz}, J=8.7 \mathrm{~Hz}, \mathrm{H}_{6}\right), 7.71\left(\mathrm{~d}, 1 \mathrm{H}, J=8.7 \mathrm{~Hz}, \mathrm{H}_{5}\right) \cdot{ }^{13} \mathrm{C}-\mathrm{NMR}\left(\mathrm{CDCl}_{3}\right) \delta: 26.7$ (q), 29.7 (q), 48.7 (t), 73.5 (s), 74.9 (s), 74.9 (s), 86.0 (d), 106.9 (d), 113.1 (d), 117.0 (s), 127.6 (d), 161.3 (s), 163.0 (s), 193.8 (s). IR (film) cm $\mathrm{cm}^{-1}: 3322$ (m, HC =C), 2979 (s), 2934 (s), 2868 (sh), 2187 (sh), 2111(vs, C $\equiv \mathrm{C}$ ), 1733 (vs, CO), 1652 (sh), 1546 (m), 1455 (m), 1375 (m), 1253 (w), 1178 (m), 1097 (w), 1031 (m). MS m/z (\%): 258 (M+1 19), 192 (33), 177 (100), 137 (54), 107 (32), 67 (53). Anal. Calcd for $\mathrm{C}_{16} \mathrm{H}_{18} \mathrm{O}_{3}:$ C, 74.39; H, 7.02. Found: C, 74.19; H, 7.29.

4-(4-Chlorophenyl)-2,2-dimethyl-7-(2-methylbut-3-yn-2-yloxy)-2H-chromene (7). To a stirred solution of $5(0.2 \mathrm{~g}, 0.77 \mathrm{mmol})$, in dry ether $(3 \mathrm{~mL})$ was added 4chlorophenylmagnesium bromide $(2.5 \mathrm{~mL}, 2 \mathrm{mmol}, 0.8 \mathrm{M})$ under argon. The resulting mixture was stirred and refluxed for $18 \mathrm{~h}$. After cooling, the organic phase was washed with $1 \mathrm{~N} \mathrm{HCl}$ $(3 \times 5 \mathrm{~mL})$. The solvent was removed under reduced pressure to give an oil of crude alcohol 6 . To this oily residue was added $2 \mathrm{~N} \mathrm{HCl}(5 \mathrm{~mL})$ and refluxed for 3 hours. After cooling, it was extracted with ethyl acetate $(3 \times 10 \mathrm{~mL})$, washed with saturated aqueous $\mathrm{NaHCO}_{3}$ and dried $\left(\mathrm{Na}_{2} \mathrm{SO}_{4}\right)$. After concentration, the residue was purified by flash column chromatography (silica $\mathrm{gel}=10 \mathrm{~g}$, hexane $/ \mathrm{EtOAc}=5: 1)$ to give $7(0.25 \mathrm{~g}, 0.71 \mathrm{mmol}, 90 \%)$ as a colorless crystal, $\mathrm{mp}$ 114-115 ${ }^{\circ} \mathrm{C}$ (hexane-ethyl acetate). ${ }^{1} \mathrm{H}-\mathrm{NMR}\left(\mathrm{CDCl}_{3}\right) \delta: 1.46\left(\mathrm{~s}, 6 \mathrm{H}, 2 \mathrm{CH}_{3}\right), 1.66(\mathrm{~s}, 6 \mathrm{H}$, $\left.\mathrm{C} \equiv \mathrm{CC}\left(\mathrm{CH}_{3}\right)_{2}\right), 2.58(\mathrm{~s}, 1 \mathrm{H}, \mathrm{CH} \equiv \mathrm{C}), 5.49(\mathrm{~s}, 1 \mathrm{H}, 3-\mathrm{CH}), 6.73\left(\mathrm{~d}, 1 \mathrm{H}, J=2.4 \mathrm{~Hz}, \mathrm{H}_{8}\right), 6.80$ (dd, $\left.1 \mathrm{H}, J=2.4 \mathrm{~Hz}, J=8.4 \mathrm{~Hz}, \mathrm{H}_{6}\right), 6.84\left(\mathrm{~d}, 1 \mathrm{H}, J=8.4 \mathrm{~Hz}, \mathrm{H}_{5}\right), 7.27$ (d, 2H, $\left.J=8.4 \mathrm{~Hz}, \mathrm{Ar}\right), 7.35$ (d, $2 \mathrm{H}, J=8.4 \mathrm{~Hz}, \mathrm{Ar}) .{ }^{13} \mathrm{C}-\mathrm{NMR}\left(\mathrm{CDCl}_{3}\right) \delta: 27.5$ (q), 29.6 (q), 72.3 (s), 73.9 (s), 76.0 (s), 86.0 (d), 
109.5 (d), 113.3 (d), 117.0 (s), 125.4 (d), 126.9 (d), 127.4 (d), 128.4 (d), 128.5 (d), 130.0 (d),

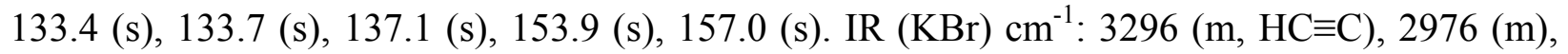
2927 (s), 2854 (m), 2150 (w, C $\equiv \mathrm{C}), 1606$ (vs), 1494 (s), 1450 (w), 1352 (m), 1138 (vs), 1002 (m), $811(\mathrm{~m}), 646$ (v). MS m/z (\%): $354\left(\mathrm{M}^{+}+2,24\right), 352\left(\mathrm{M}^{+}, 74\right), 337$ (60), 286 (38), 284 (51), 271 (100), 242 (37), 222 (43), 188 (60), 152 (87), 133 (39), 91 (42). Anal. Calcd for $\mathrm{C}_{22} \mathrm{H}_{21} \mathrm{ClO}_{2}$ : C, 74.89; H, 6.00. Found: C, 74.70; H, 6.18. Other compounds (8/9a-d, 12a-b and 14/15a-c) were prepared similarly.

4-(4-Chlorobenzylidene)-3,4-dihydro-2,2-dimethyl-7-(2-methylbut-3-yn-2-yloxy)-2Hchromene (8a-exo) and 4-(4-Chlorobenzyl)-7-(2-methylbut-3-yn-2-yloxy)-2,2-dimethyl-2Hchromene (9a-endo). A colorless oil (90\%) as mixture of exo ( $E$ and $Z, 95: 5)$ and endo isomers (56:44). ${ }^{1} \mathrm{H}-\mathrm{NMR}\left(\mathrm{CDCl}_{3}\right)$ 8a (exo-isomer) $\delta: 1.22_{(\mathrm{Z})}$ and $1.27_{(E)}\left(2 \mathrm{~s}, 6 \mathrm{H}, 2-\mathrm{CH}_{3}\right), 1.66(\mathrm{~s}, 6 \mathrm{H}$, $\left.\mathrm{C} \equiv \mathrm{CC}\left(\mathrm{CH}_{3}\right)_{2}\right), 2.59(\mathrm{~s}, 1 \mathrm{H}, \mathrm{CH} \equiv \mathrm{C}), 2.66\left(\mathrm{~d}, 2 \mathrm{H}, J=1.2 \mathrm{~Hz}, 3-\mathrm{CH}_{2}\right), 6.74\left(\mathrm{~d}, 1 \mathrm{H}, J=2.4 \mathrm{~Hz}, \mathrm{H}_{8}\right)$, $6.77\left(\mathrm{dd}, 1 \mathrm{H}, J=2.4 \mathrm{~Hz}, J=8.4 \mathrm{~Hz}, \mathrm{H}_{6}\right), 6.99$ (bs, $\left.1 \mathrm{H}, 4-\mathrm{ClPh}-\mathrm{CH}=\mathrm{C}\right), 7.20$ (d, 2H, $J=8.4 \mathrm{~Hz}$, $\left.\mathrm{H}_{3,5}-4-\mathrm{ClPh}\right), 7.31$ (d, 2H, $\left.J=8.4 \mathrm{~Hz}, \mathrm{H}_{2,6}-4-\mathrm{ClPh}\right), 7.48_{(Z)}$ and 7.50(E) $\left(2 \mathrm{~d}, 1 \mathrm{H}, J=8.4 \mathrm{~Hz}, \mathrm{H}_{5}\right)$; 9a (endo-isomer) $\delta$ : $1.40\left(\mathrm{~s}, 6 \mathrm{H}, 2-\mathrm{CH}_{3}\right), 1.62\left(\mathrm{~s}, 6 \mathrm{H}, \mathrm{C} \equiv \mathrm{CC}\left(\mathrm{CH}_{3}\right)_{2}\right), 2.56(\mathrm{~s}, 1 \mathrm{H}, \mathrm{HC} \equiv \mathrm{C}), 3.64$ $\left(\mathrm{s}, 2 \mathrm{H}, 4-\mathrm{ClPh}-\mathrm{CH}_{2}\right), 5.17(\mathrm{~s}, 1 \mathrm{H}, 3-\mathrm{CH}), 6.66\left(\mathrm{dd}, 1 \mathrm{H}, J=2.4 \mathrm{~Hz}, J=8.4 \mathrm{~Hz}, \mathrm{H}_{6}\right), 6.73(\mathrm{~d}, 1 \mathrm{H}$, $\left.J=2.4 \mathrm{~Hz}, \mathrm{H}_{8}\right), 6.95$ (d, 1H, $\left.J=8.4 \mathrm{~Hz}, \mathrm{H}_{5}\right), 7.16$ (d, 2H, $\left.J=8.4 \mathrm{~Hz}, \mathrm{H}_{3,5}-4-\mathrm{ClPh}\right), 7.26$ (d, 2H, $J=$ $\left.8.4 \mathrm{~Hz}, \mathrm{H}_{2,6}-4-\mathrm{ClPh}\right) .{ }^{13} \mathrm{C}-\mathrm{NMR}\left(\mathrm{CDCl}_{3}\right)$ 8a/9a (exo/endo isomers) $\delta$ : 26.6 (q), 27.9 (q), 29.6 (q), $37.1(\mathrm{t}), 37.2$ (t), $72.1(\mathrm{~s}), 72.2(\mathrm{~s}), 73.9$ (s), 74.0 (s), 75.2 (s), 76.2 (s), 86.0 (d), 109.2 (d), 109.3 (d), 113.0 (d), 113.6 (d), 116.2 (s), 116.9 (s), 120.2 (d), 123.5 (d), 124.3 (d), 127.50 (d), 128.3 (d), 128.5 (d), 130.1 (d), 130.2 (s), 130.6 (d), 131.1 (s), 132.0 (s), 132.1 (s), 136.0 (s),

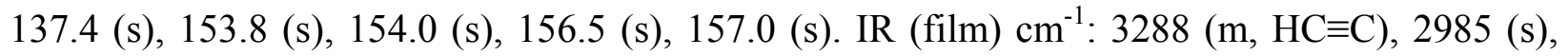

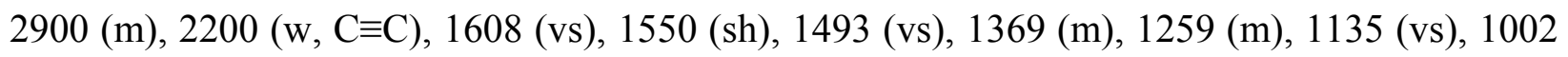
(s), 780 (m). MS m/z (\%): $368\left(\mathrm{M}^{+}+2,32\right), 366$ (100), 351 (59), 302 (48) 284 (98), 250 (26), 189 (20), 175 (57), 124 (99), 89 (78), 67 (87). Anal. Calcd for $\mathrm{C}_{23} \mathrm{H}_{23} \mathrm{ClO}_{2}$ : C, 75.30; H, 6.32. Found: C, 75.53; H, 6.45 .

4-(3-Chlorobenzylidene)-3,4-dihydro-2,2-dimethyl-7-(2-methylbut-3-yn-2-yloxy)- $2 \mathrm{H}$-chromene (8bexo) and 4-(3-Chlorobenzyl)-7-(2-methylbut-3-yn-2-yloxy)-2,2-dimethyl-2H-chromene (9b-endo). A colorless oil $(85 \%)$ as mixture of exo $(E$ and $Z, 70: 30)$ and endo isomers $(59: 41) .{ }^{1} \mathrm{H}-\mathrm{NMR}$ $\left(\mathrm{CDCl}_{3}\right) \mathbf{8 b}$ (exo-isomer) $\delta: 1.27_{(\mathrm{Z})}$ and $1.28_{(E)}\left(2 \mathrm{~s}, 6 \mathrm{H}, 2-\mathrm{CH}_{3}\right), 1.66\left(\mathrm{~s}, 6 \mathrm{H}, \mathrm{C} \equiv \mathrm{CC}\left(\mathrm{CH}_{3}\right)_{2}\right), 2.59$ $(\mathrm{s}, 1 \mathrm{H}, \mathrm{CH} \equiv \mathrm{C}), 2.65_{(\mathrm{Z})}$ and 2.66 $(E)\left(2 \mathrm{~d}, 2 \mathrm{H}, J=1.2 \mathrm{~Hz}, 3-\mathrm{CH}_{2}\right), 6.74\left(\mathrm{~d}, 1 \mathrm{H}, J=2.4 \mathrm{~Hz}, \mathrm{H}_{8}\right), 6.77$ (dd, $\left.1 \mathrm{H}, J=2.4 \mathrm{~Hz}, J=8.4 \mathrm{~Hz}, \mathrm{H}_{6}\right), 6.97$ (bs, 1H, 3-ClPh-CH=C), 7.10-7.30 (m, 4H, 3-ClPh), $7.50_{(Z)}$ and $7.51_{(E)}\left(2 \mathrm{~d}, 1 \mathrm{H}, J=8.4 \mathrm{~Hz}, \mathrm{H}_{5}\right)$; $9 \mathrm{~b}$ (endo-isomer) $\delta: 1.41\left(\mathrm{~s}, 6 \mathrm{H}, 2-\mathrm{CH}_{3}\right), 1.62(\mathrm{~s}, 6 \mathrm{H}$, $\left.\mathrm{C} \equiv \mathrm{CC}\left(\mathrm{CH}_{3}\right)_{2}\right), 2.56(\mathrm{~s}, 1 \mathrm{H}, \mathrm{HC} \equiv \mathrm{C}), 3.64\left(\mathrm{~s}, 2 \mathrm{H}, 3-\mathrm{ClPh}-\mathrm{CH}_{2}\right), 5.20(\mathrm{~s}, 1 \mathrm{H}, 3-\mathrm{CH}), 6.65(\mathrm{dd}, 1 \mathrm{H}$, $\left.J=2.4 \mathrm{~Hz}, J=8.4 \mathrm{~Hz}, \mathrm{H}_{6}\right), 6.72\left(\mathrm{~d}, 1 \mathrm{H}, J=2.4 \mathrm{~Hz}, \mathrm{H}_{8}\right), 6.94\left(\mathrm{~d}, 1 \mathrm{H}, J=8.4 \mathrm{~Hz}, \mathrm{H}_{5}\right), 7.10-7.30$ (m, $4 \mathrm{H}, 3-\mathrm{ClPh}) .{ }^{13} \mathrm{C}-\mathrm{NMR}\left(\mathrm{CDCl}_{3}\right)$ 8b/9b (exo/endo isomers) $\delta: 27.0$ (q), 28.0 (q), 29.6 (q), 37.1 $(\mathrm{t}), 37.5(\mathrm{t}), 72.2(\mathrm{~s}), 72.9$ (s), 73.9 (s), 74.0 (s), 75.3 (s), 76.2 (s), 85.9 (d), 86.0 (d), 109.2 (d), 109.3 (d), 113.1 (d), 113.6 (d), 116.1 (s), 116.9 (s), 120.1 (d), 123.6 (d), 124.4 (d), 126.4 (d), 126.5 (d), 127.0 (d), 127.4 (d), 127.5 (d), 127.7 (d), 127.8 (d), 128.9 (d), 129.4 (d), 129.7 (d), 129.9 (s), 130.7 (s), 131.8 (s), 134.0 (s), 139.4 (s), 141.1 (s), 153.8 (s), 154.1 (s), 156.5 (s), 157.2 


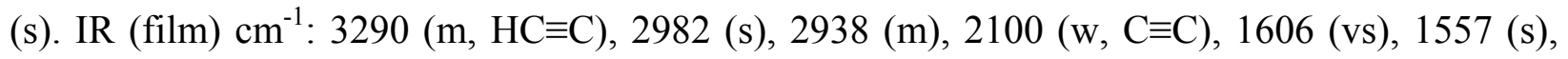
1493 (vs), 1434 (s), 1380 (s), 1252 (s), 1129 (vs), 996 (s), 879 (m), 765 (s). MS: m/z (\%): 368 $\left(\mathrm{M}^{+}+2,12\right), 364\left(\mathrm{M}^{+}, 37\right), 350$ (14), 301 (37), 298 (73), 283 (100), 132 (14), 124 (22), 90 (13), 66 (24). Anal. Calcd for $\mathrm{C}_{23} \mathrm{H}_{23} \mathrm{ClO}_{2}$ : C, 75.30; $\mathrm{H}, 6.32$. Found: $\mathrm{C}, 75.55 ; \mathrm{H}, 6.14$.

4-(2-Chlorobenzylidene)-3,4-dihydro-2,2-dimethyl-7-(2-methylbut-3-yn-2-yloxy)-2Hchromene (8c-exo) and 4-(2-Chlorobenzyl)-7-(2-methylbut-3-yn-2-yloxy)-2,2-dimethyl-2Hchromene (9c-endo). A colorless oil (82\%) as mixture of exo ( $E$ and $Z, 65: 35)$ and endo isomers (57:43). ${ }^{1} \mathrm{H}-\mathrm{NMR}\left(\mathrm{CDCl}_{3}\right)$ 8c (exo-isomer) $\delta$ : $1.27_{(Z)}$ and $1.28_{(E)}\left(2 \mathrm{~s}, 6 \mathrm{H}, 2-\mathrm{CH}_{3}\right), 1.66(\mathrm{~s}, 6 \mathrm{H}$, $\left.\mathrm{C} \equiv \mathrm{CC}\left(\mathrm{CH}_{3}\right)_{2}\right), 2.55_{(\mathrm{Z})}$ and $2.56_{(E)}\left(2 \mathrm{~d}, 2 \mathrm{H}, J=1.2 \mathrm{~Hz}, 3-\mathrm{CH}_{2}\right), 2.60(\mathrm{~s}, 1 \mathrm{H}, \mathrm{CH} \equiv \mathrm{C}), 6.74(\mathrm{~d}, 1 \mathrm{H}$, $\left.J=2.4 \mathrm{~Hz}, \mathrm{H}_{8}\right), 6.78$ (dd, $1 \mathrm{H}, J=2.4 \mathrm{~Hz}, J=8.4 \mathrm{~Hz}, \mathrm{H}_{6}$ ), 7.05 (bs, 1H, 2-ClPh-CH=C), 7.15-7.42 $(\mathrm{m}, 4 \mathrm{H}, 2-\mathrm{ClPh}), 7.55_{(\mathrm{Z})}$ and $7.56_{(E)}\left(2 \mathrm{~d}, 1 \mathrm{H}, J=8.4 \mathrm{~Hz}, \mathrm{H}_{5}\right)$; 9c (endo-isomer) $\delta: 1.41(\mathrm{~s}, 6 \mathrm{H}$, $\left.2-\mathrm{CH}_{3}\right), 1.62\left(\mathrm{~s}, 6 \mathrm{H}, \mathrm{C} \equiv \mathrm{CC}\left(\mathrm{CH}_{3}\right)_{2}\right), 2.56(\mathrm{~s}, 1 \mathrm{H}, \mathrm{CH} \equiv \mathrm{C}), 3.77\left(\mathrm{~s}, 2 \mathrm{H}, 2-\mathrm{ClPh}-\mathrm{CH}_{2}\right), 5.08(\mathrm{~s}, 1 \mathrm{H}$, $3-\mathrm{CH}), 6.68\left(\mathrm{dd}, 1 \mathrm{H}, J=2.4 \mathrm{~Hz}, J=8.4 \mathrm{~Hz}, \mathrm{H}_{6}\right), 6.72\left(\mathrm{~d}, 1 \mathrm{H}, J=2.4 \mathrm{~Hz}, \mathrm{H}_{8}\right), 6.95$ (d, $1 \mathrm{H}, J=8.4$ $\left.\mathrm{Hz}, \mathrm{H}_{5}\right), 7.15-7.42(\mathrm{~m}, 4 \mathrm{H}, 2-\mathrm{ClPh}) .{ }^{13} \mathrm{C}-\mathrm{NMR}\left(\mathrm{CDCl}_{3}\right)$ 8c/9c (exo/endo isomers) $\delta: 26.6(\mathrm{q})$, 27.9 (q), 29.6 (q), 34.9 (t), 37.4 (t), 72.2 (s), 73.8 (s), 74.0 (s), 75.5 (s), 76.3 (s), 85.9 (d), 109.2 (d), 113.1 (d), 113.6 (d), 116.2 (s), 117.1 (s), 119.0 (d), 123.4 (d), 124.7 (d), 126.2 (d), 126.8 (d), 127.3 (d), 127.7 (d), 127.9 (d), 129.4 (d), 130.5 (d), 130.9 (s), 131.0 (d), 131.4 (s), 131.8 (s), 134.5 (s), 135.8 (s), 136.6 (s), 153.9 (s), 154.1 (s), 156.4 (s), 157.1 (s). IR (KBr) cm cm $^{-1} 3288$ (m, $\mathrm{HC} \equiv \mathrm{C}), 2982$ (s), 2100 (w, C $\equiv \mathrm{C}), 1604$ (vs), 1485 (s), 1366 (m), 1250 (m), 1128 (vs), 993 (s), 751 (s). MS m/z (\%): $368\left(\mathrm{M}^{+}+2,3\right), 366\left(\mathrm{M}^{+}, 10\right), 350$ (10), 300 (45), 285 (100), 221 (11), 175 (16), 125 (18). Anal. Calcd for $\mathrm{C}_{23} \mathrm{H}_{23} \mathrm{ClO}_{2}$ : C, 75.30; H, 6.32. Found: C, 75.35; H, 6.52.

4-(2,3-Dichlorobenzylidene)-3,4-dihydro-2,2-dimethyl-7-(2-methylbut-3-yn-2-yloxy)- $\quad \mathbf{2 H}$ chromene (8d-exo) and 4-(2,3-Dichlorobenzyl)-2,2-dimethyl-7-(2-methylbut-3-yn-2-yloxy)$\mathbf{2 H}$-chromene (9d-endo). A colorless oil (75\%) as mixture of exo ( $E$ and $Z, 75: 25)$ and endo isomers (60:40). ${ }^{1} \mathrm{H}-\mathrm{NMR}\left(\mathrm{CDCl}_{3}\right) 8 \mathrm{~d}$ (exo-isomer) $\delta: 1.27_{(\mathrm{Z})}$ and $1.28_{(E)}\left(2 \mathrm{~s}, 6 \mathrm{H}, 2-\mathrm{CH}_{3}\right), 1.66$ $\left(\mathrm{s}, 6 \mathrm{H}, \mathrm{C} \equiv \mathrm{CC}\left(\mathrm{CH}_{3}\right)_{2}\right), 2.49_{(\mathrm{Z})}$ and $2.53_{(E)}\left(2 \mathrm{~d}, J=1.2 \mathrm{~Hz}, 2 \mathrm{H}, 3-\mathrm{CH}_{2}\right), 2.58_{(\mathrm{Z})}$ and $2.61_{(E)}(2 \mathrm{~s}, 1 \mathrm{H}$, $\mathrm{CH} \equiv \mathrm{C}), 6.74\left(\mathrm{~d}, 1 \mathrm{H}, J=2.4 \mathrm{~Hz}, \mathrm{H}_{8}\right), 6.79\left(\mathrm{dd}, 1 \mathrm{H}, J=2.4 \mathrm{~Hz}, J=8.4 \mathrm{~Hz}, \mathrm{H}_{6}\right), 7.01$ (bs, $1 \mathrm{H}, 2,3-$ $\left.\mathrm{Cl}_{2} \mathrm{Ph}-\mathrm{CH}=\mathrm{C}\right), 7.08-7.38\left(\mathrm{~m}, 3 \mathrm{H}, 2,3-\mathrm{Cl}_{2} \mathrm{Ph}\right), 7.48_{(\mathrm{Z})}$ and $7.55_{(E)}\left(\mathrm{d}, 1 \mathrm{H}, J=8.4 \mathrm{~Hz}, \mathrm{H}_{5}\right)$; 9d (endoisomer) $\delta: 1.40\left(\mathrm{~s}, 6 \mathrm{H}, 2-\mathrm{CH}_{3}\right), 1.62\left(\mathrm{~s}, 6 \mathrm{H}, \mathrm{C} \equiv \mathrm{CC}\left(\mathrm{CH}_{3}\right)_{2}\right), 2.57(\mathrm{~s}, 1 \mathrm{H}, \mathrm{CH} \equiv \mathrm{C}), 3.80(\mathrm{~s}, 2 \mathrm{H}, 2,3-$ $\left.\mathrm{Cl}_{2} \mathrm{Ph}_{-} \mathrm{CH}_{2}\right), 5.10(\mathrm{~s}, 1 \mathrm{H}, 3-\mathrm{CH}), 6.68\left(\mathrm{dd}, 1 \mathrm{H}, J=2.4 \mathrm{~Hz}, J=8.4 \mathrm{~Hz}, \mathrm{H}_{6}\right), 6.73(\mathrm{~d}, 1 \mathrm{H}, J=2.4 \mathrm{~Hz}$, $\left.\mathrm{H}_{8}\right), 6.92\left(\mathrm{~d}, 1 \mathrm{H}, J=8.4 \mathrm{~Hz}, \mathrm{H}_{5}\right), 7.08-7.38\left(\mathrm{~m}, 3 \mathrm{H}, 2,3-\mathrm{Cl}_{2} \mathrm{Ph}\right) .{ }^{13} \mathrm{C}-\mathrm{NMR}\left(\mathrm{CDCl}_{3}\right) \mathbf{8 d} / \mathbf{9 d}$ (exo/endo isomers) $\delta: 26.6(\mathrm{q}), 27.9(\mathrm{q}), 29.6(\mathrm{q}), 35.9(\mathrm{t}), 37.5(\mathrm{t}), 72.2(\mathrm{~s}), 73.9(\mathrm{~s}), 74.0(\mathrm{~s})$, 75.5 (s), 76.3 (s), 85.9 (d), 86.0 (d), 109.2 (d), 113.1 (d), 113.6 (d), 115.8 (s), 116.8 (s), 118.9 (d), 123.4 (d), 124.8 (d), 126.6 (d), 127.2 (d), 127.5 (s), 128.7 (d), 128.8 (d), 129.2 (d), 130.1 (s), 132.5 (s), 132.7 (s), 133.1 (s), 133.2 (s), 138.1 (s), 139.1 (s), 153.8 (s), 154.2 (s), 156.6 (s), 157.3

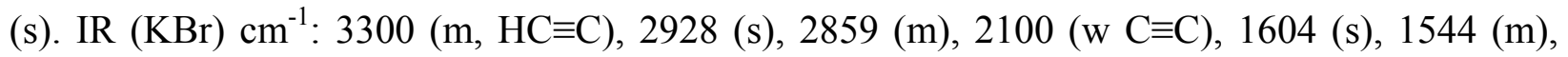
1455 (m), 1236 (s), 1128 (s), 1033 (m), 850 (m), 751 (s). MS m/z (\%): $403\left(\mathrm{M}^{+}+3,15\right), 402$ $\left(\mathrm{M}^{+}+2,65\right), 401\left(\mathrm{M}^{+}+1,24\right), 400\left(\mathrm{M}^{+}, 95\right), 384$ (69), 319 (98), 255 (21), 251 (17), 177 (20), 175 (70), 158 (100), 134 (52), 91 (47). Anal. Calcd for $\mathrm{C}_{23} \mathrm{H}_{22} \mathrm{Cl}_{2} \mathrm{O}_{2}$ : C, 68.83; $\mathrm{H}, 5.53$. Found: C, 68.53; H, 5.85. 
2,2,8,8-Tetramethyl-8H-pyrano[2,3-f]chroman-4-one (10). A solution of alkyne 5 (0.2 g, $0.7 \mathrm{mmol})$ in anhydrous $N, N$-dimethylaniline $(0.5 \mathrm{~mL})$ was heated under argon at $170{ }^{\circ} \mathrm{C}$ for $30 \mathrm{~min}$. After cooling at room temperature, water was added to the reaction mixture and extracted with ethyl acetate $(3 \times 15 \mathrm{~mL})$. The combined organic phase was dried $\left(\mathrm{Na}_{2} \mathrm{SO}_{4}\right)$ followed by evaporation of solvent under reduced pressure to obtain crude oil. This crude oil was purified by column chromatography (silicagel, $30 \mathrm{~g}$ ) eluted with hexane/ethyl acetate (8:1) to provide the compound $\mathbf{1 0}(0.17 \mathrm{~g}, 0.67 \mathrm{mmol}, 95 \%)$ as yellow oil. ${ }^{1} \mathrm{H}-\mathrm{NMR}\left(\mathrm{CDCl}_{3}\right) \delta: 1.42$ $\left(\mathrm{s}, 6 \mathrm{H}, 2 \mathrm{CH}_{3}\right), 1.43\left(\mathrm{~s}, 6 \mathrm{H}, 2 \mathrm{CH}_{3}\right), 2.63\left(\mathrm{~s}, 2 \mathrm{H}, \mathrm{CH}_{2}\right), 5.56\left(\mathrm{~d}, 1 \mathrm{H}, J=10.0 \mathrm{~Hz}, \mathrm{H}_{9}\right), 6.41(\mathrm{~d}, 1 \mathrm{H}$, $\left.J=8.6 \mathrm{~Hz}, \mathrm{H}_{6}\right), 6.62\left(\mathrm{~d}, 1 \mathrm{H}, J=10.0 \mathrm{~Hz}, \mathrm{H}_{10}\right), 7.67\left(\mathrm{~d}, 1 \mathrm{H}, J=8.6 \mathrm{~Hz}, \mathrm{H}_{5}\right) .{ }^{13} \mathrm{C}-\mathrm{NMR}\left(\mathrm{CDCl}_{3}\right) \delta$ : 26.8 (q), 28.2 (q), 48.5 (t), 79.6 (s), 109.6 (s), 110.2 (d), 114.0 (s), 116.0 (d), 127.4 (d), 128.4 (d), 156.1 (s), 159.7 (s), 191.1 (s). IR (KBr) cm $\mathrm{cm}^{-1}: 2978$ (s), 2924 (m), 1730 (sh), 1685 (vs, C=O), 1650 (m), 1597 (vs), 1435 (s), 1376 (s), 1283 (s), 1175 (m), 1111 (s), 1062 (s), 890 (v), 723 (m). MS m/z (\%): $258\left(\mathrm{M}^{+}, 15\right) 243$ (56), 187 (60), 186 (84), 149 (14), 102 (14), 84 (100). Anal. Calcd for $\mathrm{C}_{16} \mathrm{H}_{18} \mathrm{O}_{3}$ : C, 74.39; H, 7.02. Found: C, 74.65; H, 6.89.

4-Phenyl-2,2,8,8-tetramethyl-2H,8H-pyrano[2,3-f]chromene (12a). A colorless oil (84\%). ${ }^{1} \mathrm{H}-\mathrm{NMR}\left(\mathrm{CDCl}_{3}\right) \delta: 1.43\left(\mathrm{~s}, 6 \mathrm{H}, 2 \mathrm{CH}_{3}\right), 1.48\left(\mathrm{~s}, 6 \mathrm{H}, 2 \mathrm{CH}_{3}\right), 5.46\left(\mathrm{~s}, 1 \mathrm{H}, \mathrm{H}_{3}\right), 5.58(\mathrm{~d}, 1 \mathrm{H}$, $\left.J=10.0 \mathrm{~Hz}, \mathrm{H}_{9}\right), 6.29$ (d, 1H, J=8.4 Hz, H ), 6.72 (d, 1H, J=8.4 Hz, H5), 6.76(d, 1H, J=10.0 Hz, $\left.\mathrm{H}_{10}\right), 7.32-7.38$ (m, 5H, Ph). ${ }^{13} \mathrm{C}-\mathrm{NMR}\left(\mathrm{CDCl}_{3}\right) \delta: 27.7$ (q), 27.9 (q), 76.1 (s), 76.3 (s), 108.3 (d), 110.5 (s), 115.6 (s), 116.9 (d), 125.7 (d), 126.0 (d), 127.3 (d), 128.3 (d), 128.8 (d), 129.0 (d), 135.0 (s), 138.7 (s), 149.1 (s), 153.9 (s). IR (KBr) cm $\mathrm{cm}^{-1}$ : 3055 (w), 297o (vs), 2928 (s), 2855 (sh), 1631 (s), 1602 (vs), 1479 (vs), 1372 (s), 1320 (s), 1210 (m), 1112 (s), 1073 (vs), 892 (m), 764 (s), 701 (s). MS m/z (\%): $318\left(\mathrm{M}^{+}, 3\right), 303$ (16), 120 (11), 118 (16), 85 (100). Anal. Calcd for $\mathrm{C}_{22} \mathrm{H}_{22} \mathrm{O}_{2}$ : C, 82.99; $\mathrm{H}, 6.96$. Found: $\mathrm{C}, 82.73 ; \mathrm{H}, 7.24$.

4-(4-Chlorophenyl)-2,2,8,8-tetramethyl-2H,8H-pyrano[2,3-f $]$ chromene (12b). A colorless oil $(86 \%) .{ }^{1} \mathrm{H}-\mathrm{NMR}\left(\mathrm{CDCl}_{3}\right) \delta: 1.43\left(\mathrm{~s}, 6 \mathrm{H}, 2 \times \mathrm{CH}_{3}\right), 1.48\left(\mathrm{~s}, 6 \mathrm{H}, 2 \mathrm{CH}_{3}\right), 5.45\left(\mathrm{~s}, 1 \mathrm{H}, \mathrm{H}_{3}\right), 5.61(\mathrm{~d}$, $\left.1 \mathrm{H}, J=10.0 \mathrm{~Hz}, \mathrm{H}_{9}\right), 6.30$ (d, $\left.1 \mathrm{H}, J=8.4 \mathrm{~Hz}, \mathrm{H}_{6}\right), 6.71\left(\mathrm{~d}, 1 \mathrm{H}, J=8.4 \mathrm{~Hz}, \mathrm{H}_{5}\right), 6.73$ (d, $1 \mathrm{H}, J=10.0$ $\mathrm{Hz}, \mathrm{H}_{10}$ ), 7.27 (d, 2H, J=7.2 Hz, H3,5-4-ClPh), 7.34 (d, 2H, J=7.2 Hz, $\mathrm{H}_{2,6}-4-\mathrm{ClPh}$ ); ${ }^{13} \mathrm{C}-\mathrm{NMR}$ $\left(\mathrm{CDCl}_{3}\right)$ 8: 27.6 (q), 27.9 (q), 76.1 (s), 76.3 (s), 108.4 (d), 110.6 (s), 115.2 (s), 116.8 (d), 125.4 (d), 126.2 (d), 128.4 (d), 129.2 (d), 130.1 (d), 133.4 (s), 134.1 (s), 137.1 (s), 149.1 (s), 154.0 (s). IR (KBr) cm : $^{-1} 2966$ (s), 2922 (s), 2859 (sh), 1630 (m), 1591(vs), 1474 (s), 1367 (m), 1284 (vs), 1216 (s), 1114 (s), 1075 (vs), 816 (s), 763 (s). MS m/z (\%): $354\left(\mathrm{M}^{+}+2,8\right), 352\left(\mathrm{M}^{+}, 24\right) 338$ (65), 335 (100), 162 (12). Anal. Calcd for $\mathrm{C}_{22} \mathrm{H}_{21} \mathrm{ClO}_{2}$ : C, 74.89; H, 6.00. Found: C, 74.64; H, 6.24.

4-Benzylidene-3,4-dihydro-2,2,8,8-tetramethyl-2H,8H-pyrano[2,3-f]chromene (14a-exo) and 4-Benzyl-2,2,8,8-tetramethyl-2H,8H-pyrano[2,3-f $f$ chromene (15a-endo). A colorless oil $(82 \%)$ as mixture of exo $(E$ and $Z, 90: 10)$ and endo isomers $(70: 30)$. ${ }^{1} \mathrm{H}-\mathrm{NMR}\left(\mathrm{CDCl}_{3}\right)$ 14a (exoisomer) $\delta: 1.27_{(Z)}$ and $1.28_{(E)}\left(2 \mathrm{~s}, 6 \mathrm{H}, 2-\mathrm{CH}_{3}\right), 1.43_{(Z)}$ and $1.44_{(E)}\left(2 \mathrm{~s}, 6 \mathrm{H}, 8-\mathrm{CH}_{3}\right), 2.72(\mathrm{~d}, 2 \mathrm{H}, J=$ $\left.1.2 \mathrm{~Hz}, 3-\mathrm{CH}_{2}\right), 5.49$ (d, 1H, $\left.J=9.9 \mathrm{~Hz}, \mathrm{H}_{9}\right), 6.43\left(\mathrm{~d}, 1 \mathrm{H}, J=8.4 \mathrm{~Hz}, \mathrm{H}_{6}\right), 6.96(\mathrm{bs}, \mathrm{Ph}-\mathrm{CH}=\mathrm{C})$, 7.18-7.37 (m, 5H, Ph), $7.38\left(\mathrm{~d}, 1 \mathrm{H}, J=8.4 \mathrm{~Hz}, \mathrm{H}_{5}\right)$; 15a (endo-isomer) $\delta: 1.41\left(\mathrm{~s}, 6 \mathrm{H}, 2-\mathrm{CH}_{3}\right)$, $1.42\left(\mathrm{~s}, 6 \mathrm{H}, 8-\mathrm{CH}_{3}\right) 3.70\left(\mathrm{~s}, 2 \mathrm{H}, \mathrm{Ph}-\mathrm{CH}_{2}\right), 5.11(\mathrm{~s}, 1 \mathrm{H}, 3-\mathrm{CH}), 5.50\left(\mathrm{~d}, 1 \mathrm{H}, J=9.9 \mathrm{~Hz}, \mathrm{H}_{9}\right), 6.28$ $\left(\mathrm{d}, 1 \mathrm{H}, J=8.4 \mathrm{~Hz}, \mathrm{H}_{6}\right), 6.68\left(\mathrm{~d}, 1 \mathrm{H}, J=9.9 \mathrm{~Hz}, \mathrm{H}_{10}\right), 6.71\left(\mathrm{~d}, 1 \mathrm{H}, J=9.9 \mathrm{~Hz}, \mathrm{H}_{10}\right), 6.89$ (d, $1 \mathrm{H}, J=$ 
8.4 Hz, $\left.\mathrm{H}_{5}\right), 7.18-7.37(\mathrm{~m}, 5 \mathrm{H}, \mathrm{Ph}) .{ }^{13} \mathrm{C}-\mathrm{NMR}$ 14a/15a (exo/endo isomers) $\left(\mathrm{CDCl}_{3}\right) \delta: 26.8(\mathrm{q})$, 27.9 (q), $28.1(\mathrm{q}), 37.2$ (t), 38.0 (t), 75.5 (s), 76.0 (s), 76.3 (s), 107.5 (d), 108.5 (d), 110.1 (s), 110.2 (s), 114.7 (s), 115.4 (s), 116.9 (d), 117.1 (d), 120.9 (d), 123.6 (d), 124.2 (d), 125.9 (d), 126.3 (d), 128.2 (d), 128.3 (d), 128.4 (d), 128.8 (d), 128.9 (d), 129.4 (d), 137.6 (s), 139.1 (s), 141.8 (s), 148.9 (s), 149.2 (s), 153.7 (s), 153.9 (s). IR (KBr) cm ${ }^{-1}: 2974$ (s), 2925 (m), 1685 (sh), 1636 (s), 1596 (vs), 1479 (s), 1430 (m), 1372 (s), 1310 (w), 1211 (m), 1157 (m), 1117 (vs), 1064 (s), 805 (s), 703 (s). MS m/z (\%): 332 (M+11), 315 (33), 228 (11), 180 (47), 101 (13), 89 (100). Anal. Calcd for $\mathrm{C}_{23} \mathrm{H}_{24} \mathrm{O}_{2}$ : C, 83.10; H, 7.28. Found: C, 82.87; H, 7.37.

4-(4-Chlorobenzylidene)-3,4-dihydro-2,2,8,8-tetramethyl-2H,8H-pyrano[2,3-f]chromene (14b-exo) and 4-(4-Chlorobenzyl)-2,2,8,8-tetramethyl-2H,8H-pyrano[2,3- $f$ chromene (15bendo). A colorless oil (80\%) as mixture of exo $(E$ and $Z, 80: 20)$ and endo isomers $(66: 34) .{ }^{1} \mathrm{H}-$ $\operatorname{NMR}\left(\mathrm{CDCl}_{3}\right)$ 14b (exo-isomer) $\delta: 1.27_{(\mathrm{Z})}$ and $1.29_{(E)}\left(2 \mathrm{~s}, 6 \mathrm{H}, 2-\mathrm{CH}_{3}\right), 1.43\left(\mathrm{~s}, 6 \mathrm{H}, 8-\mathrm{CH}_{3}\right), 2.65$ $\left(\mathrm{d}, 2 \mathrm{H}, J=1.2 \mathrm{~Hz}, 3-\mathrm{CH}_{2}\right), 5.56\left(\mathrm{~d}, 1 \mathrm{H}, J=9.9 \mathrm{~Hz}, \mathrm{H}_{9}\right), 6.43\left(\mathrm{~d}, 1 \mathrm{H}, J=8.6 \mathrm{~Hz}, \mathrm{H}_{6}\right) 6.68(\mathrm{~d}, 1 \mathrm{H}, J$ $\left.=9.9 \mathrm{~Hz}, \mathrm{H}_{10}\right), 6.91(\mathrm{~s}, 4-\mathrm{ClPh}-\mathrm{CH}=\mathrm{C}), 7.08_{(Z)}$ and $7.09_{(E)}\left(2 \mathrm{~d}, 2 \mathrm{H}, J=8.3 \mathrm{~Hz}, \mathrm{H}_{3,5}-4-\mathrm{ClPh}\right)$, 7.35-7.39 (m, 2H, 4-ClPh), $7.41\left(2 \mathrm{~d}, 1 \mathrm{H}, J=8.5 \mathrm{~Hz}, \mathrm{H}_{5}\right.$ ); 15b (endo-isomer) $\delta: 1.41$ (s, 6H, 2$\left.\mathrm{CH}_{3}\right), 1.42\left(\mathrm{~s}, 6 \mathrm{H}, 8-\mathrm{CH}_{3}\right), 3.61\left(\mathrm{~s}, 2 \mathrm{H}, 4-\mathrm{ClPh}-\mathrm{CH}_{2}\right), 5.20(\mathrm{~s}, 1 \mathrm{H}, 3-\mathrm{CH}), 5.57(\mathrm{~d}, 1 \mathrm{H}, J=9.9 \mathrm{~Hz}$, $\left.\mathrm{H}_{9}\right), 6.27\left(\mathrm{~d}, 1 \mathrm{H}, J=8.4 \mathrm{~Hz}, \mathrm{H}_{6}\right), 6.69$ (d, $\left.1 \mathrm{H}, J=9.9 \mathrm{~Hz}, \mathrm{H}_{10}\right), 6.78\left(\mathrm{~d}, 1 \mathrm{H}, J=8.5 \mathrm{~Hz}, \mathrm{H}_{5}\right), 7.35-$ 7.39 (m, 4H, 4-ClPh). ${ }^{13} \mathrm{C}-\mathrm{NMR}$ 14b/15b (exo/endo isomers) $\left(\mathrm{CDCl}_{3}\right) \delta: 27.7$ (q), 28.0 (q), 28.2 (q), $37.1(\mathrm{t}), 37.2(\mathrm{t}), 75.4(\mathrm{~s}), 76.0(\mathrm{~s}), 76.1$ (s), 76.9 (s), $108.2(\mathrm{~d}), 109.1$ (d), 110.3 (s), 115.0 (s), 116.8 (d), 117.0 (d), 119.6 (d), 123.4 (d), 124.2 (d), 126.4 (d), 128.3 (d), 128.6 (d), 128.9 (d), 129.0 (d), 130.0 (d), 130.1 (s), 130.5 (s), 130.6 (d), 131.3 (s), 131.9 (s), 136.1 (s), 137.5 (s), 149.9 (s), 150.0 (s), 153.7 (s), 154.0 (s). IR (KBr) cm : $^{-1} 2974$ (s), 2925 (m), 1685 (sh), 1631 (s), 1591 (s), 1470 (vs), 1410 (m), 1377 (s), 1275 (m), 1211 (s), 1160 (m), 1118 (vs), 1059 (s), 893 (m), 815 (m), 722 (m). MS m/z (\%): $368\left(\mathrm{M}^{+}+2,21\right), 366\left(\mathrm{M}^{+}, 64\right), 349$ (39), 150 (12), 125 (11), 98 (68), 82 (100). Anal. Calcd for $\mathrm{C}_{23} \mathrm{H}_{23} \mathrm{ClO}_{2}$ : C, 75.30; H, 6.32. Found: C, 75.52; H, 6.04.

4-(3-Chlorobenzylidene)-3,4-dihydro-2,2,8,8-tetramethyl-2H,8H-pyrano[2,3-f]chromene (14c-exo) and 4-(3-Chlorobenzyl)-2,2,8,8-tetramethyl-2H,8H-pyrano[2,3-f]chromene (15cendo). A colorless oil (79\%) as mixture of exo $(E$ and $Z, 95: 5)$ and endo isomers $(59: 41) .{ }^{1} \mathrm{H}-$ $\operatorname{NMR}\left(\mathrm{CDCl}_{3}\right)$ 14c (exo-isomer) $\delta: 1.27_{(\mathrm{Z})}$ and $1.29_{(\mathrm{E})}\left(2 \mathrm{~s}, 6 \mathrm{H}, 2-\mathrm{CH}_{3}\right), 1.45\left(\mathrm{~s}, 6 \mathrm{H}, 8-\mathrm{CH}_{3}\right), 2.56$ (d, $\left.2 \mathrm{H}, J=1.2 \mathrm{~Hz}, 3-\mathrm{CH}_{2}\right), 5.54\left(\mathrm{~d}, 1 \mathrm{H}, J=9.9 \mathrm{~Hz}, \mathrm{H}_{9}\right), 6.29$ (d, 1H, J=8.4 Hz, H ), 6.68 (d, 1H, $\left.J=9.9 \mathrm{~Hz}, \mathrm{H}_{10}\right), 7.00(\mathrm{~s}, 1 \mathrm{H}, 3-\mathrm{Cl} \mathrm{Ph}-\mathrm{CH}=\mathrm{C}), 7.15-7.31(\mathrm{~m}, 4 \mathrm{H}, 3-\mathrm{ClPh}), 7.45(\mathrm{~d}, 1 \mathrm{H}, J=8.4 \mathrm{~Hz}$, $\mathrm{C}_{5}$ ); 15c (endo-isomer) $\delta$ : $1.41\left(\mathrm{~s}, 6 \mathrm{H}, 2-\mathrm{CH}_{3}\right), 1.42\left(\mathrm{~s}, 6 \mathrm{H}, 8-\mathrm{CH}_{3}\right), 3.76\left(\mathrm{~s}, 2 \mathrm{H}, 3-\mathrm{ClPh}_{-} \mathrm{CH}_{2}\right)$, $5.07(\mathrm{~s}, 1 \mathrm{H}, 3-\mathrm{CH}), 5.56\left(\mathrm{~d}, 1 \mathrm{H}, J=9.9 \mathrm{~Hz}, \mathrm{H}_{9}\right), 6.44\left(\mathrm{~d}, 1 \mathrm{H}, J=8.4 \mathrm{~Hz}, \mathrm{H}_{6}\right), 6.70(\mathrm{~d}, 1 \mathrm{H}, J=9.9$ $\left.\mathrm{Hz}, \mathrm{H}_{10}\right), 6.50\left(\mathrm{~d}, 1 \mathrm{H}, J=8.4 \mathrm{~Hz}, \mathrm{C}_{5}\right), 7.15-7.31$ (m, 4H, 3-ClPh). ${ }^{13} \mathrm{C}-\mathrm{NMR}\left(\mathrm{CDCl}_{3}\right) \mathbf{1 4 c / 1 5 c}$ (exo/endo isomers) $\delta: 26.8(\mathrm{q}), 27.9(\mathrm{q}), 28.0(\mathrm{q}), 35.0(\mathrm{t}), 37.4(\mathrm{t}), 75.6(\mathrm{~s}), 76.0(\mathrm{~s}), 76.1(\mathrm{~s})$, 76.5 (s), 108.3 (d), 109.0 (d), 110.0 (s), 110.2 (s), 114.3 (s), 115.2 (s), 116.8 (d), 117.0 (d), 118.4 (d), 123.3 (d), 124.5 (d), 126.1 (d), 126.2 (d), 126.8 (d), 127.7 (d), 127.8 (d), 128.4 (d), 128.9 (d), 129.3 (d), 130.5 (d), 131.0 (d), 131.9 (s), 134.3 (s), 134.5 (s), 136.0 (s), 136.7 (s), 138.90 (s), 148.8 (s). 149.3 (s), 153.6 (s), 154.2 (s). IR (KBr) cm ${ }^{-1}: 2969$ (vs), 2928 (m), 1634 (m), 1590 (s), 1474 (s), 1371 (s), 1268 (s), 1209 (s), 1174 (s), 1111 (vs), 1057 (vs), 811 (m), 747 (s). MS m/z 
(\%): $368\left(\mathrm{M}^{+}+2,13\right), 366\left(\mathrm{M}^{+}, 40\right), 351$ (41), 250 (18), 173 (13), 157 (24), 128 (32), 123 (100), 90 (55). Anal. Calcd for $\mathrm{C}_{23} \mathrm{H}_{23} \mathrm{ClO}_{2}$ : C, 75.30; H, 6.32. Found: C, 75.14; H, 6.54.

\section{Acknowledgements}

This research was supported by a grant from INSF (Iran National Science Foundation, No. 83181). The author is indebted to Miss Javidnia, and Mr. Abdi for their helps in taking Mass, NMR and IR spectra, respectively.

\section{References and Notes}

1. Lee, K. Y.; Nam, D. H.; Moon, C. S.; Seo, S. H.; Lee, J. Y.; Lee, Y. S. Eur. J. Med. Chem. 2006, 41, 991.

2. Sang, S.; Lambert, J. D.; Tian, S.; Hong, J.; Hou, J.; Ryu, J.; Stark, R. E.; Rosen, R. T.; Huang, M.; Yang, C. S.; Ho, C. Bioorg. \& Med. Chem. 2004, 12, 459.

3. Sairafianpour, M.; Kayser, O.; Christensen, J.; Asfa, M.; Stark, M. W.; Jaroszewski, J. W. J. Nat. Prod. 2002, 65, 1754.

4. Dawood, K. M.; Fuchigami, T. J. Org. Chem. 2001, 66, 7691.

5. Sheu, Y. W.; Chiang, L. C.; Chen, I. S.; Chen, Y.C.; Tsai, I. L. Planta Med. 2005, 71, (12) 1165.

6. Ernst-Russell, M. A.; Chai, C. L. L.; Wardlaw, J. H.; Elix, J. A. J. Nat. Prod. 2000, 63129.

7. Arkhipov, V.V.; Prykhodko, A. O.; Dolu, A. G.; Khylya, V. P.; Yarmoluk, S. M. Biopolymers \& Cell 2003, 19, 93.

8. An, J.; Chen, Y.; Huang, Z.; J. Biol. Chem. 2004, 279, 19133.

9. Kemnitzer, W.; Drewe, J.; Jiang, S.; Zhang, H.; Wang, Y.; Zhao, J.; Jia, S.; Herich, J.; Labreque, D.; Storer, R.; Meerovitch, K.; Bouffard, D.; Rej, R.; Denis, R.; Blais, C.; Lamothe, S.; Attardo, G.; Gourdeau, H.; Tseng, B.; Kasibhatla, S.; Cai, S. X. J. Med. Chem. 2004, 47, 6299.

10. Iyer, I.; Shah, G. Ind. J. Chem. 1967, 6, 227.

11. Sangaiah, R.; Gold, A. J. Org. Chem. 1987, 52, 3205.

12. Hiessböck, R.; Wolf, C.; Richter, E.; Hitzler, M.; Chiba, P.; Kratzel, M.; Ecker, G. J. Med. Chem. 1999, 42, 1921.

13. Paquette, L.; Wiedeman, P. E.; Bulman-Page, P. C. J. Org. Chem. 1988, 53, 1441.

14. Gupta, A.; Dwivedy, A.; Keshri, G.; Sharma, R.; Balapure, A. K.; Singh, M. M.; Ray, S. Bioorg. \& Med. Chem. 2006, 16, 6006.

15. Xie, L.; Crimmins, M. T. ; Lee, K.Tetrahedron Lett. 1995, 36, 4529.

16. Mosmann, T. J. Immunol. Meth. 1983, 65, 55. 